\title{
A new mixed mode fracture test specimen covering positive and negative values of T-stress
}

\author{
M. M. Mirsayar*
}

Zachry Department of Civil Engineering, Texas A\&M University, College Station, TX 77843-3136, USA

\begin{tabular}{|c|c|}
\hline $\begin{array}{l}\text { A R T I C L E I N F O } \\
\end{array}$ & A B S T R A C T \\
\hline $\begin{array}{l}\text { Article history: } \\
\text { Received September 20, } 2013 \\
\text { Received in Revised form } \\
\text { October, } 14,2013 \\
\text { Accepted } 22 \text { February } 2014 \\
\text { Available online } \\
25 \text { February } 2014\end{array}$ & $\begin{array}{l}\text { A new fracture test specimen is suggested and analyzed using finite element method. The mode } \\
\text { I and mode II stress intensity factors as well as the T-stress were calculated for three geometries } \\
\text { and loading conditions. It is shown that the specimen, called single edge cracked ring (SECR), } \\
\text { covers different mixed mode loading conditions from pure mode I to pure mode II. The SECR } \\
\text { specimen also covers negative and positive values of T-stresses. From the practical view point, } \\
\text { the suggested specimen can be used easily for mixed mode II fracture tests. }\end{array}$ \\
\hline $\begin{array}{l}\text { Keywords: } \\
\text { Brittle fracture mechanics } \\
\text { SECR specimen } \\
\text { Mixed mode loading conditions } \\
\text { T-stress } \\
\text { Numerical analyses }\end{array}$ & \\
\hline & (C) 2014 Growing Science Ltd. All rights reserved. \\
\hline
\end{tabular}

\section{Introduction}

In many industrial and engineering structures mixed mode brittle fracture is the major reason for the catastrophic failures. In order to study the mixed mode brittle fracture, one can employ theoretical fracture criteria (Erdogan \& Sih, 1963; Sih, 1974; Hussain et al., 1974; Smith et al., 2000, Gomez et al. 2009; Ayatollahi \& Aliha 2011) or experimental approaches. Researchers usually use laboratory specimens because that the fracture experiments on real components may be difficult or expensive. A suitable laboratory specimen should be able to provide real state of the stress field adjacent the crack tip and also cover all mixed mode loading conditions from pure mode I $\left(K_{\mathrm{II}}=0\right)$ to pure mode II $\left(K_{\mathrm{I}}\right.$ $=0)$. Heretofore, several cracked specimens have been studied by many researchers for mixed mode fracture experiments to determinate the fracture toughness and crack propagation angle such as Brazilian disk (BD), semi-circular bend (SCB) and four points bend specimens (Chang et al., 2002;

* Corresponding author. Tel.: +1 (979) 7776096

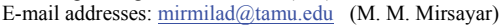


Khan \& Al- Shayea, 2000; Lim et al., 1994; Shahani \& Tabatabaei, 2008, Aliha \& Ayatollahi, 2009). On the other hand, it is now well established that the first non-singular elastic stress term (i.e. $T$ stress) has a considerable influence on the fracture toughness and crack propagation direction under mixed mode loading conditions in linear elastic crack problems. Among them (Ayatollahi \& Aliha 2009), presented a generalized maximum tangential stress (GMTS) criterion for fracture in brittle materials under mixed mode loading conditions which takes into account the effect of $T$-stress as well as the singular stress terms (stress intensity factors $K_{\mathrm{I}}$ and $K_{\mathrm{II}}$ ). Many experimental studies on different laboratory specimens such as BD and SCB indicate the significant influence of $T$-stress in prediction of fracture toughness and direction of fracture initiation (Ayatollahi \& Aliha, 2006, 2009). However, some of laboratory specimens have their own limitations which may result in errors in fracture test results. For example, some of them are not able to completely cover the mixed mode loading conditions from pure mode I to pure mode II or may require complicated fixtures for loading. Among various laboratory specimens, the circular ones are more preferable than other shapes because they can be loaded easily. Aliha et al. (2008) have suggested a ring shaped specimen containing double internal cracks covering the only negative values of $T$-stresses. The positive value of $T$-stress is also very important as it may be the reason of the instability in mode I crack growth (Cotterell \& Rice, 1980) or reduction in the mixed mode I/II fracture toughness (Ayatollahi et al. 2006; Aliha et al. 2012) . In this work, a ring shaped specimen with an external crack is suggested which can produce positive and negative value of $T$-stresses in different mixed mode loading conditions.

\section{New fracture test specimen}

The elastic stress field near the crack tip can be characterized by the stress intensity factors, $K_{\mathrm{I}}$ (mode I stress intensity factor) and $K_{\mathrm{II}}$ (mode II stress intensity factor), $T$-stress and the higher order terms (Williams, 1957). Fig. 1 shows the single edge cracked ring (SECR) specimen with external radius of $R_{1}$ and internal radius of $R_{2}$, crack length of $a$ and crack orientation angle of $\alpha$. The specimen is loaded under radial force in different loading angles $\phi$ to create mixed mode loading conditions.

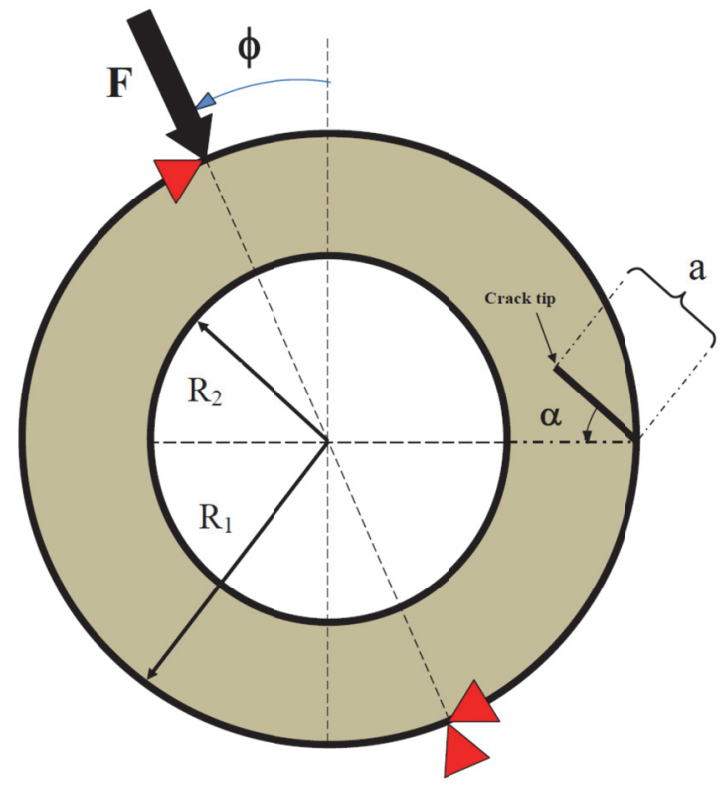

Fig. 1. Geometry and loading conditions for a single edge cracked ring (SECR) specimen

Mixed mode loading conditions, pure mode I, pure mode II as well as negative and positive values of T-stresses can be obtained by varying parameters $a / \Delta R, \alpha$ and $\phi$, where $\Delta R=R_{l}-R_{2}$. 


\section{Numerical analysis of test specimen}

The (SECR) specimen described in previous section is modeled numerically to show the ability of providing mixed mode loading conditions. The specimen is modeled for three different geometries as given in Table 1 . The radiuses $R_{1}$ and $R_{2}$ are selected $50 \mathrm{~mm}$ and $65 \mathrm{~mm}$, respectively for all models.

Table 1

Lengths and orientation angles of cracks in SECR specimens

\begin{tabular}{lll}
\hline Case & $\boldsymbol{a}(\mathrm{mm})$ & $\alpha$ (degrees) \\
\hline 1 & 8 & $0^{\circ}$ \\
2 & 10 & $30^{\circ}$ \\
3 & 13 & $45^{\circ}$ \\
\hline
\end{tabular}

The specimens were modeled and analyzed by commercial finite element software ABAQUS 6.9 using 8-node iso-parametric elements (CPS8R) in plane stress condition. A typical finite element mesh pattern used for the SECR specimen and the closer view of the elements adjacent the crack tip are shown in Fig. 2 for the case-2. A very fine mesh was used in the region near the crack tip due to high stress/strain gradient resulting from singular stress.

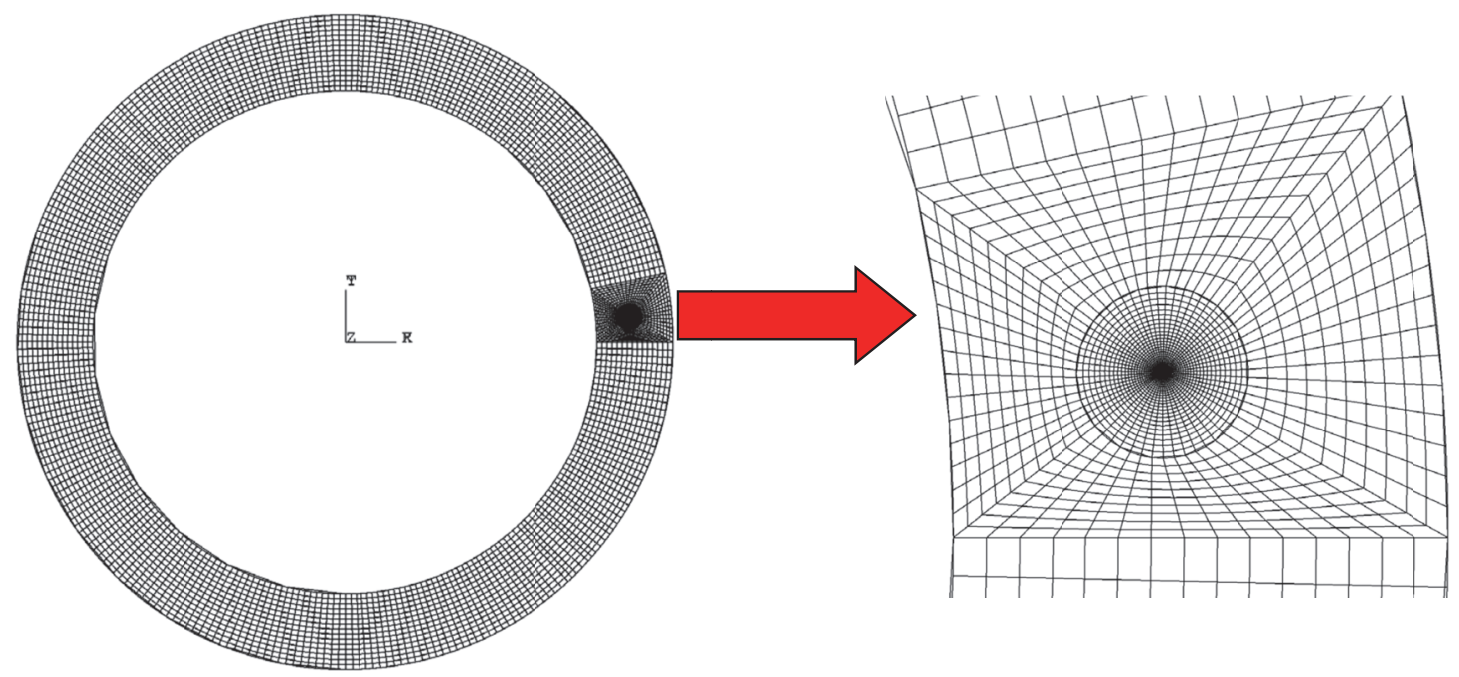

Fig. 2. Typical finite element mesh used for modeling the SECR specimen in case -2

The thickness of models and the concentrated force were assumed equal to $\mathrm{t}=1 \mathrm{~mm}$ and $100 \mathrm{~N}$, respectively. The material constants Poisson's ratio and Young's modulus were also selected $v=0.3$ and $E=1 \mathrm{~N} / \mathrm{mm}^{2}$ (taken arbitrary). Dimensionless parameters $M^{\mathrm{e}}$ and normalized values $Y_{\mathrm{I}}, Y_{\mathrm{II}}$ and normalized value of $T$-stress, $T^{*}$, are defined as follows:

$$
\begin{aligned}
& M^{e}=\frac{2}{\pi} \tan ^{-1}\left(\frac{K_{I}}{K_{I I}}\right) \\
& T^{*}(a / \Delta R, \alpha, \phi)=T \frac{2(\Delta R) t}{F} \\
& Y_{I}(a / \Delta R, \alpha, \phi)=\frac{K_{I}}{\sqrt{\pi a}} \frac{2(\Delta R) t}{F} \\
& Y_{I I}(a / \Delta R, \alpha, \phi)=\frac{K_{I I}}{\sqrt{\pi a}} \frac{2(\Delta R) t}{F}
\end{aligned}
$$


The parameter $\mathrm{M}^{\mathrm{e}}$ varies between zero and 1 showing the contribution of each fracture mode in a typical loading conditions. The parameters $Y_{\mathrm{I}}, Y_{\mathrm{II}}$ and $T^{*}$ were calculated for three cases in different loading angles of $\phi$ between pure mode I and pure mode II ( $\left.\phi_{\text {I }}, \phi_{\text {II }}\right)$.

\section{Results and Discussion}

The variation of normalized stress intensity factors, $Y_{\mathrm{I}}$ and $Y_{\mathrm{II}}$, versus mode mixity parameter $M^{\mathrm{e}}$ is illustrated in Fig. 3(a) and (b). It is seen that the specimen covers different mixed mode conditions from pure mode I to pure mode II in each case. It can be seen that the geometry parameter $Y_{\mathrm{I}}$ for case- 1 is larger than case- 2 and case- 3 . It means that the loading condition for case- 1 leads to larger bending moment around the crack tip and more crack tip opening than two other cases. The conditions corresponding to pure mode I and pure mode II in all three cases are given in Table 2.

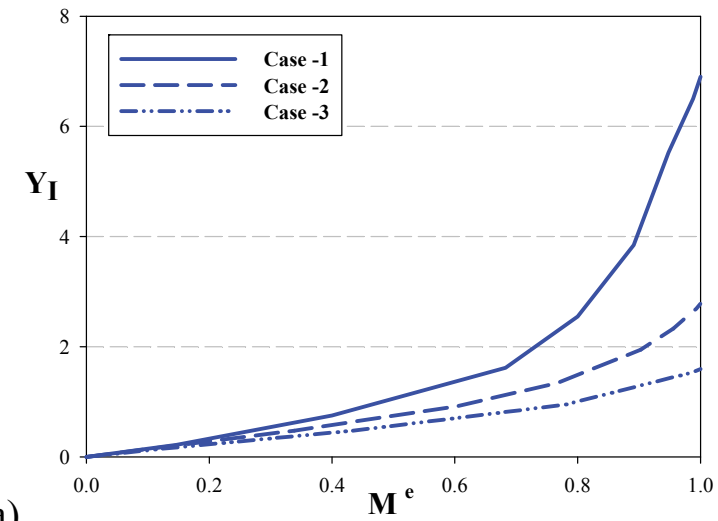

a)

Fig. 3. Variations of normalized stress intensity factors from pure mode I to pure mode II. (a) $Y_{I}$ versus $\mathrm{M}^{\mathrm{e}}$, (b) $\mathrm{Y}_{\mathrm{II}}$ versus $\mathrm{M}^{\mathrm{e}}$.

Table 2

Loading angles and normalized stress intensity factors corresponding to pure mode I and pure mode II

\begin{tabular}{lcccc}
\hline Case & $\phi_{\mathrm{I}}$ & $Y_{\mathrm{I}}\left(@, Y_{\mathrm{II}}=0\right)$ & $\phi_{\mathrm{II}}$ & $Y_{\mathrm{II}}\left(@, Y_{\mathrm{I}}=0\right)$ \\
\hline 1 & $0^{\circ}$ & 6.91 & $45.8^{\mathrm{o}}$ & 0.95 \\
2 & $40.5^{\circ}$ & 2.78 & $54.1^{\circ}$ & 1.02 \\
3 & $51.7^{\circ}$ & 1.59 & $60.8^{\mathrm{o}}$ & 0.83 \\
\hline
\end{tabular}

Variation of $T^{*}$ versus $M^{\mathrm{e}}$ is shown in Fig. 4 for each case. It can be seen that $T^{*}$ is always a positive value for case- 1 and a negative value for case-3. For case-2, $T^{*}$ is negative for pure mode II conditions and approaches zero by increasing $M^{\mathfrak{e}}$ and finally becomes a small positive value in pure mode I conditions. It also can be seen that for all the three cases, there is a tendency for the $T^{*}$ to be a more positive value in pure mode I than pure mode II conditions. The $T^{*}$ corresponding to pure mode I and pure mode II for each case is given in Table 3.

Table 3

Normalized T-stress in pure mode I and Pure mode II conditions for three cases

\begin{tabular}{lll}
\hline Case & $T_{I}^{*}$ & $T_{I I}^{*}$ \\
\hline 1 & 2.701 & 0.751 \\
2 & 0.331 & -2.340 \\
3 & -0.963 & -3.663 \\
\hline
\end{tabular}




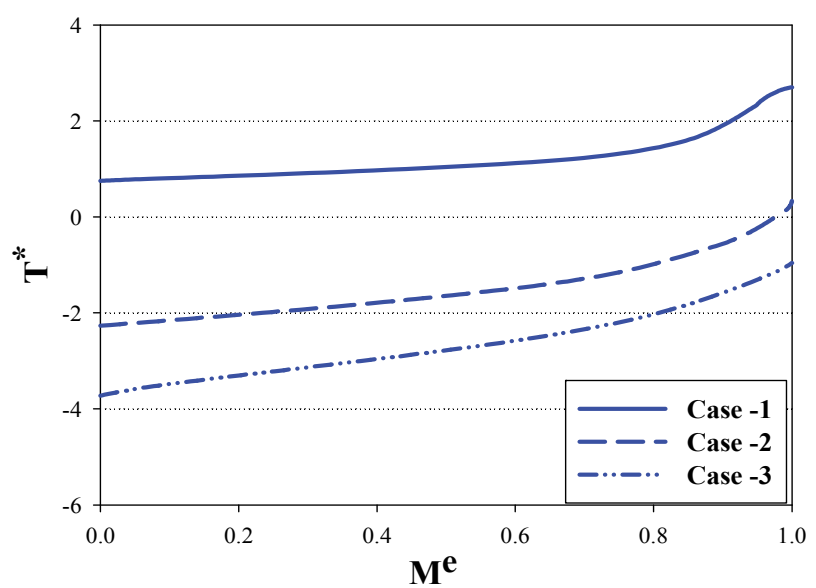

Fig. 4. Variation of $T^{*}$ values versus $M^{\mathrm{e}}$ in three cases

A dimensionless parameter called the biaxiality ratio, $B$, has been introduced by Leevers and Radon (1982) to normalize the $T$-stress relative to the stress intensity factors. For mixed mode loading conditions the biaxiality ratio can be represented as:

$$
B=\frac{T \sqrt{\pi a}}{\sqrt{\left(K_{I}\right)^{2}+\left(K_{I I}\right)^{2}}}=\frac{T^{*}}{\sqrt{\left(Y_{I}\right)^{2}+\left(Y_{I I}\right)^{2}}}
$$

The variation of biaxiality ratio versus $M^{\mathrm{e}}$ is illustrated in Fig. 5. It can be seen that the absolute value of $B$ decreases by increasing the mode mixity parameter in all three cases. It means that the contribution of $T$-stress in the near-crack-tip stresses relative to the stress intensity factors, $K_{\mathrm{I}}$ and $K_{\mathrm{II}}$, becomes more significant when mode mixity parameter approaches zero. On the other words, the highest effect of $T$-stress on distribution of stress field near the crack tip takes place in pure mode II loading.

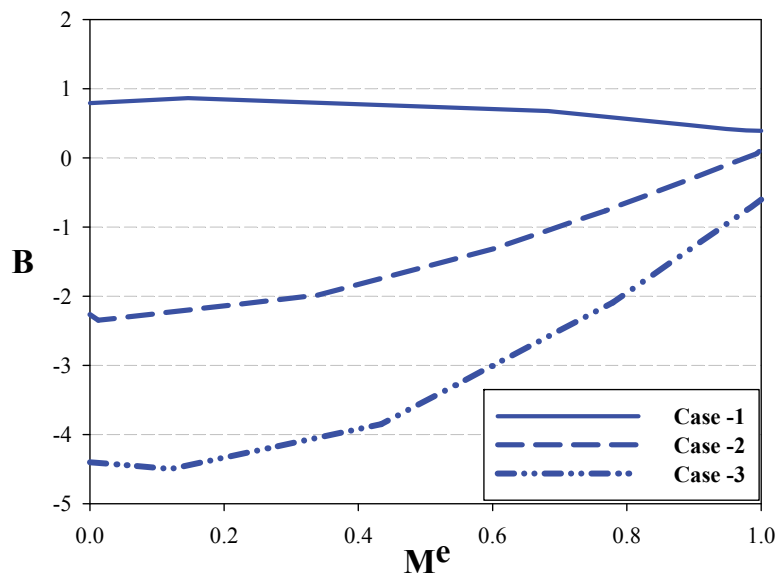

Fig. 5. Variation of biaxialy ratio, $B$, versus $M^{\mathrm{e}}$ in three different cases

The suggested specimen can be used for validation of stress based criteria for brittle materials which considers the effect of $T$-stress. For example the negative values of the $T$-stress obtained for the SECR specimens in this paper can be used to validate the theory presented by Cotterell and Rice (1980) for stable crack growth in brittle fracture and generalized MTS criterion suggested by Smith et al. (2000). 


\section{Conclusions}

A new fracture test specimen is suggested for determination of fracture parameters covering all mixed mode conditions from pure mode I to pure mode II. The specimen (called SECR) is able to provide both negative and positive values of $T$-stresses. The SECR can be used for validation of brittle fracture criteria, which consider the effect of $T$-stress as well as the stress intensity factors. The SECR can also be modeled and manufactured easily and no complicated fixtures are needed for loading.

\section{References}

Aliha, M. R. M., Ayatollahi, M. R., \& Pakzad, R. (2008). Brittle fracture analysis using a ring-shape specimen containing two angled cracks. International Journal of Fracture, 153(1), 63-68.

Aliha, M. R. M., \& Ayatollahi, M. R. (2009). Brittle fracture evaluation of a fine grain cement mortar in combined tensile-shear deformation. Fatigue \& Fracture of Engineering Materials \& Structures, 32(12), 987-994.

Aliha, M. R. M., \& Ayatollahi, M. R. (2009). Brittle fracture evaluation of a fine grain cement mortar in combined tensile-shear deformation. Fatigue \& Fracture of Engineering Materials \& Structures, 32(12), 987-994.

Aliha, M. R. M., Ayatollahi, M. R., \& Akbardoost, J. (2012). Typical upper bound-lower bound mixed mode fracture resistance envelopes for rock material. Rock mechanics and rock engineering, 45(1), 65-74.

Ayatollahi, M. R., \& Aliha, M. R. M. (2009). Mixed mode fracture in soda lime glass analyzed by using the generalized MTS criterion. International Journal of Solids and Structures, 46(2), 311-321.

Ayatollahi, M. R., \& Aliha, M. R. M. (2006). On determination of mode II fracture toughness using semicircular bend specimen. International Journal of Solids and Structures, 43(17), 5217-5227.

Ayatollahi, M. R., \& Aliha, M. R. M. (2011). Fracture analysis of some ceramics under mixed mode loading. Journal of the American Ceramic Society, 94(2), 561-569.

Ayatollahi, M. R., Aliha, M. R. M., \& Hassani, M. M. (2006). Mixed mode brittle fracture in PMMA-an experimental study using SCB specimens. Materials Science and Engineering: A, 417(1), 348-356.

Chang, S. H., Lee, C. I., \& Jeon, S. (2002). Measurement of rock fracture toughness under modes I and II and mixed-mode conditions by using disc-type specimens. Engineering Geology, 66(1), 79-97.

Cotterell, B., \& Rice, J. (1980). Slightly curved or kinked cracks. International Journal of Fracture, 16(2), 155-169.

Erdogan, F., \& Sih, G. C. (1963). On the crack extension in plates under plane loading and transverse shear. Journal of Basic Engineering, 85, 519-525.

Gómez, F. J., Elices, M., Berto, F., \& Lazzarin, P. (2009). Fracture of V-notched specimens under mixed mode (I+ II) loading in brittle materials. International journal of fracture, 159(2), 121-135.

Hussain, M. A., Pu, S. L., \& Underwood, J. (1974). Strain Energy Release Rate for a Crack Under Combined Mode I and Mode II. Fracture analysis, 560, 1.

Khan, K., \& Al-Shayea, N. A. (2000). Effect of specimen geometry and testing method on mixed mode I-II fracture toughness of a limestone rock from Saudi Arabia. Rock Mechanics and Rock Engineering, 33(3), 179-206.

Leevers, P. S., \& Radon, J. C. (1982). Inherent stress biaxiality in various fracture specimen geometries. International Journal of Fracture, 19(4), 311-325.

Lim, I. L., Johnston, I. W., Choi, S. K., \& Boland, J. N. (1994, June). Fracture testing of a soft rock with semicircular specimens under three-point bending. Part 2-mixed-mode. In International journal of rock mechanics and mining sciences \& geomechanics abstracts 31 (3), 199-212.

Shahani, A. R., \& Tabatabaei, S. A. (2008). Computation of mixed mode stress intensity factors in a four-point bend specimen. Applied Mathematical Modelling, 32(7), 1281-1288.

Sih, G.C. (1974). Strain-energy-density factor applied to mixed mode crack problems. International Journal of Fracture, 10(3), 305-321.

Smith, D. J., Ayatollahi, M. R., \& Pavier, M. J. (2001). The role of T-stress in brittle fracture for linear elastic materials under mixed-mode loading. Fatigue \& Fracture of Engineering Materials \& Structures, 24(2), 137-150.

Williams, M. L. (1961). The bending stress distribution at the base of a stationary crack. Journal of applied mechanics, 28(1), 78-82. 